Original Research Article

\title{
Knowledge, attitude and practices of pharmacovigilance among the postgraduate and undergraduate medical students in a tertiary care hospital in Central India
}

\author{
Mohit Kulmi $^{1 *}$, Pooja Reddy ${ }^{1}$, Shilpi Dhakre ${ }^{2}$, Meghna Shinde ${ }^{1}$, Chhaya Goyal ${ }^{1}$
}

\begin{abstract}
${ }^{1}$ Department of Pharmacology, Sri Aurobindo Medical College and Postgraduate Institute, Indore, Madhya Pradesh, India ${ }^{2}$ Department of Pharmacology, Maharajah's Institute of Medical Sciences, Nellimarla, Vizianagaram District, Andhra Pradesh, India
\end{abstract}

Received: 24 January 2017 Accepted: 05 February 2017

*Correspondence to:

Dr. Mohit Kulmi,

Email: mohit.kulmi@gmail.com

Copyright: (C) the author(s), publisher and licensee Medip Academy. This is an openaccess article distributed under the terms of the Creative Commons Attribution NonCommercial License, which permits unrestricted noncommercial use, distribution, and reproduction in any medium, provided the original work is properly cited.

\begin{abstract}
Background: Adverse Drug Reactions (ADRs) are one of the underestimated causes of morbidity and mortality. Monitoring of these ADRs is at the core of any pharmacovigilance program. ADR monitoring suffers from lack of reporting from health care personnels. Unless we know the current knowledge, attitude and practices of the budding doctors it's difficult to design corrective measures to improve reporting. The present study was designed to assess the knowledge, attitude and practices of pharmacovigilance and ADR reporting among undergraduate and postgraduate medical students.

Methods: This was a questionnaire-based, observational study. The questionnaire had six questions each pertaining to knowledge, attitude and practices of pharmacovigilance and ADR reporting. Factors discouraging ADR reporting were also studied. Descriptive statistics were carried out and one-way ANOVA was applied to find the statistical difference between the groups.

Results: A total of 288 subjects were approached for the study of which 229 agreed to participate. It was observed that the knowledge of the participants regarding ADR reporting and pharmacovigilance was satisfactory. 68\% of respondents felt that educational programmes have a positive effect on ADR reporting. $15 \%$ of respondents admitted of having reported an ADR. The mean scores of knowledge, attitude and practices of ADR reporting were considerably higher in postgraduates as compared to undergraduates ( $\mathrm{p}$-value $<0.05$ ).

Conclusions: The study concluded that participants of study were aware of the importance of ADR reporting but it did not reflect in their practices. There is a need to create awareness and to educate these future physicians about Pharmacovigilance.
\end{abstract}

Keywords: ADR reporting, KAP, Pharmacovigilance, PvPI

\section{INTRODUCTION}

Pharmacovigilance has been considered as an important public health activity which aims at reducing medicine related harms and is an essential component of safe medical practice. It involves detection, assessment, understanding and prevention of adverse effects or any other drug-related problems. ${ }^{1}$

Adverse drug reactions (ADRs) are considered as one of the most important cause of morbidity and mortality in healthcare setups and are contributory to the ever- increasing health care costs. ${ }^{2,3}$ In many studies ADRs are found to be accountable for up to $20 \%$ of hospital admissions. ${ }^{4,5}$ Due to ever increasing number of ADRs, the importance of Pharmacovigilance is increasing day by day. Given the importance of ADR detection and prompt treatment, monitoring of these ADRs is at the core of any pharmacovigilance program. It is imperative to identify and treat ADRs as early as possible because at many occasions it is revocable and preventable.

Although intensive efforts are currently being undertaken to strengthen the working of Pharmacovigilance 
Programme of India (PvPI), the ground reality in India is very discouraging as there is a dearth of knowledge about this field. The effectiveness and success of the Pharmacovigilance system highly depends upon the participation of all health care personnel right from patient to the medical practitioner.

The Uppsala Monitoring Center (UMC, Sweden) is the operational arm of the World Health Organization (WHO). Its 153 member countries (full members and associate members) maintain the global ADR database. ${ }^{6}$ Although, India is participating in this program, its contribution to UMC database is minimal. This is fundamentally due to the absence of a vivacious ADR monitoring system and also due to the lack of an ADR reporting culture among the health care personnel. In order to improve the reporting rate, it is important to gauge the knowledge, attitude and practices concerning ADR reporting and pharmacovigilance among the healthcare personnel. The best time to do it is probably during the under graduate and post graduate educational years as these formative years are the times when good clinical practice patterns are imbibed.

Unless we know the current knowledge, attitude and practices of these up-and-coming doctors it's difficult to design corrective measures to fulfill the unmet needs. Hence, to identify these unmet needs, we planned the present study to assess and compare the knowledge, attitude and practices of ADR reporting among the postgraduate and the undergraduate medical students.

\section{METHODS}

A questionnaire-based, observational and cross sectional study was performed at Sri Aurobindo Medical College and Postgraduate Institute (SAMC and PGI), Indore, Madhya Pradesh over a period of one month in September 2016. The study was approved by the institutional ethics committee. The study subjects were undergraduates from $2^{\text {nd }}$ and $3^{\text {rd }}$ professional year MBBS and the postgraduate residents who agreed to participate in the study.

The purpose of the study and instructions for filling out the questionnaire were explained to each respondent personally after seeking an informed consent. The questionnaire had six questions each pertaining to knowledge, attitude and practices of pharmacovigilance and ADR reporting and had an open-ended question enquiring about factors discouraging ADR reporting. The response to each question was scored as 0 for incorrect and 1 for correct with maximum score being 6 .

The data obtained was subjected to statistical analyses. Frequency of response was calculated in percentage. Mean score was calculated for responses of knowledge, attitude and practices. One-way ANOVA was applied to find the statistical difference between the groups. P-value $<0.05$ was considered as significant.

\section{RESULTS}

Two hundred and eighty-eight subjects were approached for the study of which 229 agreed to participate in the study. Study subjects consisted of 67 postgraduates from various medical and surgical branches, 83 undergraduates from 2nd professional MBBS and 79 undergraduates from 3rd professional MBBS. Demographic data characteristics are shown in the table (Table 1). The response rate of the study subjects regarding knowledge about pharmacovigilance and ADR reporting shows that significant numbers of the respondents were aware of the terms ADR and Pharmacovigilance.

Table 1: Demographic profile of the study population.

\begin{tabular}{|llll|}
\hline & $\begin{array}{l}\text { MBBS 2 }^{\text {nd }} \\
\text { Year }\end{array}$ & $\begin{array}{l}\text { MiBS 3 } \\
\text { Year }\end{array}$ & $\begin{array}{l}\text { Post- } \\
\text { graduates }\end{array}$ \\
\hline Mean Age & $20.4 \pm 0.87$ & $21.5 \pm 0.94$ & $28.4 \pm 4.85$ \\
(Mean \pm S.D.) & years & years & years \\
\hline Male:Female & $31: 52$ & $43: 36$ & $47: 20$ \\
\hline
\end{tabular}

Table 2: Knowledge about ADR reporting.

\begin{tabular}{|c|c|c|c|}
\hline \multirow[t]{2}{*}{ Knowledge about ADR reporting } & \multicolumn{3}{|c|}{ Positive Responses } \\
\hline & $\begin{array}{l}\text { MBBS 2nd Year } \\
\text { n }(\%)\end{array}$ & $\begin{array}{l}\text { MBBS 3 }{ }^{\text {rd }} \text { Year } \\
\text { n }(\%)\end{array}$ & $\begin{array}{l}\text { Postgraduates } \mathbf{n} \\
(\%)\end{array}$ \\
\hline $\begin{array}{l}\text { Familiar with the terms adverse drug reaction } \\
\text { (ADR) and Pharmacovigilance? }\end{array}$ & $78(94.0)$ & $72(91.1)$ & $62(92.5)$ \\
\hline Could define "Pharmacovigilance" correctly. & $70(84.3)$ & $71(89.9)$ & $53(79.1)$ \\
\hline $\begin{array}{l}\text { Knew that Pharmacovigilance include drugs, } \\
\text { herbal products, medical devices and vaccines. }\end{array}$ & $22(26.5)$ & $24(30.4)$ & $33(49.3)$ \\
\hline $\begin{array}{l}\text { Knowledge about the professionals responsible } \\
\text { for ADR reporting in a hospital }\end{array}$ & $39(47.0)$ & $61(77.2)$ & $31(46.3)$ \\
\hline $\begin{array}{l}\text { Knew about CDSCO as the regulatory body } \\
\text { responsible for monitoring of the ADRs in India. }\end{array}$ & $56(67.5)$ & $61(77.2)$ & $43(64.2)$ \\
\hline $\begin{array}{l}\text { Aware of the Pharmacovigilance center in our } \\
\text { institution. }\end{array}$ & $35(42.2)$ & $40(50.6)$ & $47(70.1)$ \\
\hline
\end{tabular}


Table 3: Attitude towards ADR reporting.

\begin{tabular}{|c|c|c|c|}
\hline \multirow[t]{2}{*}{ Attitude towards ADR reporting } & \multicolumn{3}{|l|}{ Favorable Responses } \\
\hline & MBBS $2^{\text {nd }}$ year n (\%) & MBBS $3^{\text {rd }}$ year n (\%) & Postgraduates n (\%) \\
\hline ADR reporting should be compulsory. & $42(50.6)$ & $53(67.1)$ & $39(58.2)$ \\
\hline $\begin{array}{l}\text { Should Pharmacovigilance be taught during } \\
\text { the undergraduate/postgraduate curriculum? }\end{array}$ & $69(83.1)$ & $61(77.2)$ & $51(76.1)$ \\
\hline $\begin{array}{l}\text { Is it necessary to report only serious and } \\
\text { unexpected reactions? }\end{array}$ & $46(55.4)$ & $46(58.2)$ & $40(59.7)$ \\
\hline $\begin{array}{l}\text { ADRs reporting may have legal } \\
\text { consequences for the reporter? }\end{array}$ & $25(30.1)$ & $54(68.4)$ & $37(55.2)$ \\
\hline $\begin{array}{l}\text { Thinks that educational programs have } \\
\text { positive effects on ADR reporting? }\end{array}$ & $59(71.1)$ & $54(68.4)$ & $43(64.2)$ \\
\hline $\begin{array}{l}\text { Believed that the topic of } \\
\text { Pharmacovigilance is well covered in your } \\
\text { curriculum? }\end{array}$ & $32(38.6)$ & $12(15.2)$ & $18(26.9)$ \\
\hline
\end{tabular}

Table 4: Practices of ADR reporting.

\begin{tabular}{|c|c|c|c|}
\hline Practices of ADR reporting & Positive Responses & & \\
\hline & MBBS $2^{\text {nd }}$ year n (\%) & MBBS $3^{\text {rd year n }(\%)}$ & Postgraduates n (\%) \\
\hline Have witnessed any ADR? & $17(20.5)$ & $13(16.5)$ & $39(58.2)$ \\
\hline Have reported any ADR? & $6(7.2)$ & $4(5.1)$ & $24(35.8)$ \\
\hline Have seen an ADR reporting form? & $9(10.8)$ & $11(13.9)$ & $19(28.4)$ \\
\hline Know where to report an ADR? & $22(26.5)$ & $9(11.4)$ & $24(35.8)$ \\
\hline Can fill an ADR form correctly? & $0(0.0)$ & $0(0.0)$ & $12(17.9)$ \\
\hline $\begin{array}{l}\text { Have attended any workshop or } \\
\text { training course on ADR reporting? }\end{array}$ & $2(2.4)$ & $4(5.1)$ & $9(13.4)$ \\
\hline
\end{tabular}

$67.5 \%$ of MBBS 2nd year students, $77.2 \%$ of MBBS 3rd year students and $64.2 \%$ of postgraduates were aware that the $\mathrm{CDSCO}$ is the regulatory body for ADR monitoring in our country. It was found that only $42.2 \%$ of MBBS $2^{\text {nd }}$ year students and $50.6 \%$ of MBBS $3^{\text {rd }}$ year students whereas $70.1 \%$ of the postgraduates were aware of the ADR monitoring centre in our institution (Table 2).

The response rate of study subjects regarding attitude towards pharmacovigilance and ADR reporting shows that $55.4 \%$ of MBBS 2nd year students, $58.2 \%$ of MBBS 3rd year students thought that only serious and unexpected reactions should be reported, $59.7 \%$ of postgraduates were of the same opinion. $30.1 \%$ of MBBS $2^{\text {nd }}$ year students, $68.4 \%$ of MBBS $3^{\text {rd }}$ year students and $55.2 \%$ of postgraduate residents were of the opinion that ADR reporting may have legal consequences for the reporter. $71.1 \%$ of MBBS 2nd year students, $68.4 \%$ of MBBS 3rd year students and $64.2 \%$ of postgraduate residents think that the educational programs do have a positive effect on ADR reporting (Table 3).

The response rate of practices of pharmacovigilance and ADR reporting among respondents showed that $20.5 \%$ of MBBS 2nd year students, $16.5 \%$ of MBBS 3rd year students and $58.2 \%$ of postgraduate residents claimed to have witnessed an ADR. 7.2\% of MBBS 2nd year students, $5.1 \%$ of MBBS $3^{\text {rd }}$ year students and $35.8 \%$ of postgraduate residents admitted of reporting an ADR. $26.5 \%$ of MBBS $2^{\text {nd }}$ year students, $11.4 \%$ of MBBS $3^{\text {rd }}$ year students and $35.8 \%$ of postgraduate residents knew exactly where to report an ADR. $17.9 \%$ of postgraduates admitted of knowing how to fill an ADR form correctly whereas none of the MBBS $2^{\text {nd }}$ and $3^{\text {rd }}$ year students knew about filling the ADR form correctly (Table 4).

Table 5: Mean score of respondents.

\begin{tabular}{|llll|}
\hline Respondents & $\begin{array}{l}\text { Knowledge } \\
(\text { mean } \pm \text { SD })\end{array}$ & $\begin{array}{l}\text { Attitude } \\
(\text { mean } \pm \text { SD })\end{array}$ & $\begin{array}{l}\text { Practice } \\
(\text { mean } \pm \text { SD })\end{array}$ \\
\hline $\begin{array}{l}\text { MBBS } 2^{\text {nd }} \text { yr } \\
(\mathrm{n}=83)\end{array}$ & $3.70 \pm 1.20$ & $2.29 \pm 0.87$ & $0.75 \pm 0.65$ \\
\hline $\begin{array}{l}\text { MBBS } 3^{\text {rd }} \mathrm{yr} \\
(\mathrm{n}=79)\end{array}$ & $4.25 \pm 1.07$ & $3.46 \pm 0.82$ & $1.83 \pm 0.77$ \\
\hline $\begin{array}{l}\text { Postgraduates } \\
(\mathrm{n}=67)\end{array}$ & $5.31 \pm 0.74$ & $4.37 \pm 0.85$ & $3.20 \pm 1.03$ \\
\hline P-Value & 0.0004 & $<0.0001$ & $<0.0001$ \\
\hline
\end{tabular}

The mean scores of knowledge, attitude and practices were calculated and the difference between the mean scores was analyzed using one-way ANOVA. The p-value obtained after ANOVA was significant $(<0.05)$ for knowledge, attitude and practices among all the three group of study subjects (Table 5).

The mean scores of MBBS $2^{\text {nd }}$ year students, MBBS $3^{\text {rd }}$ year students and postgraduate residents were compared 
(Table 5). The result of the open-ended question showed that difficulty in deciding whether an ADR has occurred or not $(42 \%)$ and a belief that a single unreported case may not affect the ADR database (36\%) were the two most common factors discouraging ADR reporting (Figure 1).

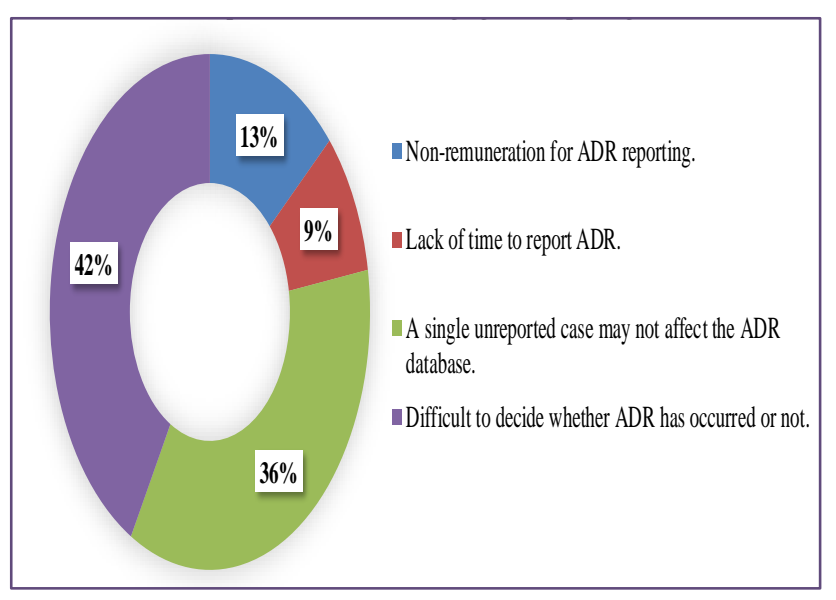

Figure 1: Factors discouraging ADR reporting.

\section{DISCUSSION}

Pharmacovigilance involves identifying the harmful effects associated with drugs and minimizing the harm. Under reporting, lack of knowledge and poor attitude in health care providers which is being identified as a major cause can lead to more patients being exposed to the harmful effects of drugs. ${ }^{7}$ Thus the current study was focused to assess knowledge, attitude and practices of ADR reporting among undergraduate and postgraduate students.

Many of the previous studies conducted in India indicated a lack of awareness about PvPI (pharmacovigilance programme of India) and ADR reporting but in the present study most of the postgraduate residents and undergraduate students showed a good theoretical knowledge about ADR reporting and pharmacovigilance. However, this knowledge is not leading to a good ADR reporting in practice. Among the undergraduates the knowledge about ADR reporting was slightly more in MBBS $3^{\text {rd }}$ professional students as compared to $2^{\text {nd }}$ professional students, this can be due to the teaching of basic principles of ADR reporting during their curriculum of pharmacology. Rajesh et al in their study showed that educational intervention in health care professionals lead to significant increase in knowledge, attitude and practice of pharmacovigilance. ${ }^{8}$

Almost half of postgraduate and maximum undergraduates believed that pharmacovigilance only includes drug related problems. Only 50\% of undergraduate were aware of the presence of ADR monitoring center in our institution. $58.2 \%$ of postgraduate residents admitted of having witnessed an ADR during their practice, despite that they did not feel the need to report it to the proper authorities as the ADR reporting from postgraduate residents was dismal at $35.8 \%$. this lack of reporting was evident from the fact that only $17.9 \%$ of postgraduates said they can fill an ADR form correctly. So, we can say that even with working knowledge of pharmacovigilance the current scenario of ADR reporting is poor. This was reflected in their attitude and practice as well. This fact is well evident in the outcome of several other studies which showed lack of attitude and practices of ADR reporting. ${ }^{9-}$ 11

Desai et al in their study showed that physicians were well aware of the adverse drug reactions and the importance of its reporting. However, under reporting of ADRs and lack of knowledge about the reporting procedure were clearly evident. ${ }^{12}$ The most common practical problem which was faced by the respondents in our study was that they were unaware of where to report the ADR, as only $35.4 \%$ of postgraduate residents knew exactly where to report ADR. This was despite the fact that $70 \%$ of them were aware of the presence of AMC (adverse drug reaction monitoring center) in the institution. This is reflected in the fact that over two-third of them never attended any workshop or conference as regards to pharmacovigilance and ADR reporting. The results obtained from our study reflected the matching trend as reported by various other studies from India. ${ }^{13-19}$

In a number of studies, the major reasons for underreporting of ADRs were found to be uncertainty concerning the causal relationship between the ADR and the drug, a belief that the ADR is not serious, and ignorance of the reporting procedure. ${ }^{20-22}$ As compared to this in our study factors like, difficulty in deciding whether an ADR has occurred or not $(42 \%)$ and nonsignificance of a single case towards the entire ADR database (36\%) (Figure 2) were the two most common factors found to be associated with under-reporting.

Lack of knowledge of where and how ADR should be reported would automatically affect reporting, therefore, awareness programs, through publicity, through notices and CME's would appear necessary to improve ADR reporting among medical practitioners. However, there was a glimmer of hope, more than half of the postgraduate residents and undergraduate students thinks that ADR reporting should be made compulsory and the topic of pharmacovigilance should be taught in detail in their curriculum. As a significant proportion of postgraduates and undergraduates felt that more educational programs about ADR reporting will have positive effect on reporting. In a study done by Chakrabarty et al it was found that ensuring proper education and frequent training of healthcare professionals by training in data collection, interpretation, risk management and action in case of serious drug event had boosted reporting of ADR. ${ }^{23}$ 
Our study results co-relate well with other studies in case of knowledge, awareness and attitude of respondents. The most common reason responsible for under-reporting was found to be obliviousness towards ADR reporting system and pharmacovigilance program. The questionnaire based studies have limitations of their own and it would be inappropriate to plan interventions based on the findings of some studies but present study uncovers the importance of ADR reporting in the present scenario of ever increasing health conscious attitude.

\section{CONCLUSION}

Our study concluded that respondents of study were only moderately aware of Pharmacovigilance and ADR reporting. There is a demanding need to create awareness and to educate residents as well as students about Pharmacovigilance as they are the future health professionals. This can be achieved by imparting knowledge and awareness of Pharmacovigilance and through implementing regular sensitization programs for the healthcare professionals.

Funding: No funding sources

Conflict of interest: None declared

Ethical approval: The study was approved by the Institutional Ethics Committee

\section{REFERENCES}

1. The Importance of Pharmacovigilance - Safety Monitoring of Medicinal Products [Internet]. Apps.who.int. 2017 [cited 11 February 2017]. Available from: http://apps.who.int/medicinedocs/en/d/Js4893e/

2. Lee A, Thomas SHL. Adverse drug reactions. In: Walker R., Edward C., editors. Clinical Pharmacy and Therapeutics. 3rd ed. Churchill Livingstone; 2003:33-46.

3. Wu WK, Pantaleo N. Evaluation of outpatient adverse drug reactions leading to hospitalization. Am J Health Syst Pharm. 2003;60:253-9.

4. Pirmohamed M, James S, Meakin S, Green C, Scott AK, Walley TJ, et al. Adverse drug reactions as cause of admission to hospital: prospective analysis of 18,820 patients. BMJ. 2004;329:15-19.

5. Lazarou J, Pomeranz BH, Corey PN. Incidence of adverse drug reactions in hospitalized patients: a meta-analysis of prospective studies. JAMA. 1998;279(15):1200-5.

6. UMC | Members [Internet]. Who-umc.org. 2017 [cited 11 February 2017]. Available from: https://www.who-umc.org/globalpharmacovigilance/members/

7. Rakesh RCP, Adepu R. Design and implementation of adverse drug reaction reporting system in community pharmacies. Indian $J$ Pharm. 2009;2(2):32-7.

8. Rajesh R, Vidyasagar S, Muralidhar Varma D. An Educational Intervention to assess Knowledge
Attitude Practice of pharmacovigilance among Health care professionals in an Indian tertiary care teaching hospital. Int J PharmTech. 2011;3(2):678-92.

9. Praveen S, Prakash RJ, Manjunath GN, Gautham MS, Kumar N. Adverse Drug Reaction reporting among medical and dental practitioners: a KAP study. Indian J Med Spec. 2013;4:10-5.

10. Vora MB, Paliwal NP, Doshi VG, Barvaliya MJ, Tripathi CB. Knowledge of adverse drug reactions and pharmacovigilance activity among the undergraduate students of Gujarat. Int J Pharm Sci Res. 2012;3:1511-5.

11. Sivanandy S, Arul Kumaran K, Rajasekaran A. Knowledge assessment in adverse drug reactions and reporting. Archives Pharm Prac. 2013;4(3):104.

12. Desai CK, Iyer G, Panchal J, Shah S, Dikshit RK. An evaluation of knowledge, attitude, and practice of adverse drug reaction reporting among prescribers at a tertiary care hospital. Perspect Clin Res. 2011;2:129-36.

13. Gupta P, Udupa A. Adverse drug reaction reporting and pharmacovigilance: Knowledge, attitudes and perceptions among the resident doctors. J Pharm Sci Res. 2011;3:1064-9.

14. Ramesh M, Parthasarathi G. Adverse drug reaction reporting: Attitudes and perceptions of medical practitioners. Asian J Pharm Clin Res. 2009;2:10-4.

15. Khan SA, Goyal C, Chandel N, Rafi M. Knowledge, attitude and practice of doctors to adverse drug reaction reporting in a teaching hospital in India: An observational study. J Nat Sci Biol Med. 2013;4:1916.

16. Hardeep, Bajaj JK, Kumar R. A survey on the knowledge, attitude and the practice of pharmacovigilance among the health care professionals in a teaching hospital in northern India. J Clin Diagn Res. 2013;7:97-9.

17. Muraraiah S, Rajarathna K, Sreedhar D, Basavalingu D, Jayanthi CR. A questionnaire study to assess the knowledge, attitude and practice of Pharmacovigilance in a paediatric tertiary care centre. J Chem Pharm Res. 2011;3:416-22.

18. Pimpalkhute SA, Jaiswal KM, Sontakke SD, Bajait CS, Gaikwad A. Evaluation of awareness about pharmacovigilance and adverse drug reaction monitoring in resident doctors of a tertiary care teaching hospital. Indian J Med Sci. 2012;66:55-61.

19. Remesh A. Identifying the reasons for under reporting of ADR: A cross sectional survey. Res J Pharm Biol Chem Sci. 2012;3:1379-86.

20. Lee KK, Chan TY, Raymond K, Critchley JA. Pharmacists' attitudes toward adverse drug reaction reporting in Hong Kong. Ann Pharmacother. 1994;28:1400-3.

21. Herdeiro MT, Figueiras A, Polonia J, Gestal-Otero JJ. Influence of pharmacists' attitudes on adverse drug reaction reporting: a case-control study in Portugal. Drug Saf. 2006;29:331-40. 
22. Okezie EO, Olufunmilayo F. Adverse drug reactions reporting by physicians in Ibadan, Nigeria. Pharmacoepidemiol Drug Saf. 2008;17:517-22.

23. Chakrabarty M, Thawani V. Starting a pharmacovigilance centre: actions for implementation. J Pharmacol Pharmacother. 2011;2(4):295-9.
Cite this article as: Kulmi M, Reddy P, Dhakre S, Shinde M, Goyal C. Knowledge, attitude and practices of pharmacovigilance among the postgraduate and undergraduate medical students in a tertiary care hospital in Central India. Int J Basic Clin Pharmacol 2017;6:1127-32. 